T his past July, the US Senate voted 78 to 15 to grant the Food and Drug Administration (FDA) authority to regulate tobacco products. The proposed, precedent setting legislation is part of a larger tax bill and is also tied to a controversial tobacco growers' buyout. In order to become law, the Senate version of the Bill, sponsored by Republican Senator Mike DeWine of Ohio and Democrat Edward Kennedy of Massachusetts, must be harmonised with a proposed, far weaker House of Representatives Bill that does not include FDA regulation. Ultimate passage of a revised Bill is not likely to occur until some time in 2005, if at all. If key senators carry out their threat to block passage of watered down House legislation, the regulatory debate may have to wait for another day, or year.

Among its many provisions, the Senate version of the Bill:

- empowers FDA to approve products that make exposure-reduction claims (PREPS)

- grants FDA authority to ban sale and distribution of any product not pre-approved by the agency and to apply nationwide product standards; states cannot impose conflicting standards

- authorises FDA to require new, larger pack warnings labels

- empowers the FDA to combat the existence of counterfeit, contraband, and other illicit tobacco products and to restrict advertising and promotions that appeal to children

- requires that FDA publish, three years after enactment, an annual list indicating "harmful and potentially harmful constituents to health" in each brand
- forbids FDA from banning tobacco sales to adults age 18 and over or from requiring that nicotine yields be reduced to zero

- prohibits manufacture of cigarettes containing additives that would be the characterising flavour other than tobacco or menthol

- allows states to regulate "time, place and manner" of cigarette advertising, but not content

- prevents manufacturers from using terms "low tar" and "light" absent advance FDA approval.

A joint statement from the American Cancer Society, the American Lung Association, the American Heart Association, and the Campaign for Tobacco-Free Kids, hailed the Senate vote "historic action". Altria, parent company of Philip Morris USA claimed the Bill would give the FDA "comprehensive, meaningful and effective authority". A New York Times editorial, by contrast, called it a "stinky deal" because of the "unseemly \$12 billion handout to tobacco growers". Other US tobacco companies are also opposed, fearing that the FDA regulation of the industry will be a de facto "Marlboro Monopoly Act", cementing Altria's market leadership by stifling marketplace competition and blocking development of arguably innovative products.

Matt Myers, president, Campaign for TobaccoFree Kids, and Dr Michael Siegel, Social and Behavioral Sciences Department, Boston University School of Public Health, argue, respectively, for and against the merits of FDA regulation of tobacco products, looking at the specifics of the Senate Bill and the general regulatory concept.

As this edition of Tobacco Control went to press, congressional tax negotiators blocked the plan to allow FDA tobacco regulation, but the issue is certain to be raised again soon. 
FDA REGULATION

\title{
Food and Drug Administration regulation of tobacco: snatching defeat from the jaws of victory
}

\author{
M Siegel
}

$\mathrm{T}$ here are two essential elements of a policy analysis: (1) it should provide an accounting of all harms and benefits of a proposed policy and then weigh these harms and benefits $^{1-3}$; and (2) it should be evidence based-it should assess the likelihood of policy effects not from the perspective of what could happen based on hypothetical considerations or pure speculation, but on documented effects or theoretical or conceptual research. ${ }^{1-3}$

Any analysis that fails to identify both harms and benefits of a policy, fails to weigh these in drawing its overall conclusion, or is not evidence based, is likely to be flawed and highly subject to bias. Thus, my approach here is to provide an accounting of the harms and benefits of the US Senate Food and Drug Administration (FDA) Bill, using an evidence based approach to assess the likely policy effects.

PROVISIONS OF BILL FOR WHICH THERE IS EVIDENCE OF A POSITIVE EFFECT ON PUBLIC HEALTH

\section{Strengthening of warning labels}

For only one provision of the Bill-the strengthening of cigarette warning labels (chapter 2, section $21(4)(a)(1))$-is there solid evidence that a positive effect on public health is likely. Research from Canada suggests that strong, graphic cigarette warning labels may increase smokers' motivation to quit. ${ }^{45}$

PROVISIONS OF BILL FOR WHICH THERE IS EVIDENCE OF A NEGATIVE EFFECT ON PUBLIC HEALTH

\section{Overall regulatory framework}

The way in which the Bill frames the problem of tobacco use will lead to an erosion of public perception of the inherent harms posed by cigarettes. The Bill frames tobacco use as a problem only insofar as tobacco companies introduce new products, make misleading health claims, or fail to comply with FDA performance standards. The Bill will result in consumers perceiving that FDA has given a stamp of approval to tobacco products, and the public's perceived level of the health risk posed by tobacco products will therefore decline.

Second, the Bill will create the public perception that the tobacco problem is taken care of. It will be virtually impossible to convince state legislators to allocate the funds necessary to support effective, statewide tobacco control programmes, interventions which have been shown to be among the most successful in reducing tobacco use. ${ }^{6}$

Third, the Bill will end any serious threat to the tobacco companies posed by current and future litigation. Tobacco companies will be able to successfully argue that they are already regulated and that there is therefore no need for any further substantial punitive damages or injunctive relief.

Fourth, the Bill will improve the public image and goodwill of tobacco companies because they will be able to use the fact of being regulated by FDA to achieve improved public opinion. Improved public image translates into an improved bottom line-increased cigarette consumption.

\section{Modified risk product provisions}

These provisions of the Bill (section 911) would have two adverse effects on public health. First, they would make it virtually impossible for any truly reduced risk product to enter the market (section 9ll(g)(1)). The Bill removes any incentive for the development of reduced risk products; instead, it freezes the market as it is.

Second, the Bill allows reduced exposure products (those which only claim to reduce exposure, not health risks) to be marketed so long as the manufacturer states that it expects the product to reduce health risks (section $91 \mathrm{l}(\mathrm{g})(2)(\mathrm{A}))$. Since the public is going to perceive that a reduced exposure product will reduce health risk, this essentially allows the company to market products as reducing health risks without any substantiation. This institutionalises the very problem that the Bill is trying to solve.

PROVISIONS OF BILL FOR WHICH THERE IS NO EVIDENCE OF AN EFFECT ON PUBLIC HEALTH, DESPITE CLAIMS TO THE CONTRARY

\section{Overall regulatory framework}

There is no evidence that giving FDA authority to regulate tobacco products will improve health. Supporters of the 1970 Federal Cigarette Labeling and Advertising $\mathrm{Act}^{8}$ thought that by giving the Federal Trade Commission the authority to regulate cigarette advertising and banning ads from television and radio, the Act would improve public health. Instead, the Bill had a detrimental effect on public health, as youth smoking increased because of the discontinuation of aggressive anti-smoking ads, ${ }^{9}$ cigarette companies were given de facto immunity from litigation for nearly three decades, and television 


\section{Debate}

advertising for cigarettes remained, in the form of sponsored motor sports and other sporting events. $^{1011}$

\section{Disclosure of cigarette constituents and arthority to issue performance standards} Knowing the names and amounts of the thousands of tobacco smoke constituents (section 904) and being able to require reductions or elimination of some of these constituents (section 907) is not going to save lives. Instead, it represents a quite absurd approach to tobacco control policy. We simply do not know which carcinogens of the more than 40 carcinogens in tobacco smoke and which toxins of the more than 4000 chemicals in tobacco smoke are responsible for what diseases, what quantities of these chemicals produce what effect, and what the effect of removing these chemical will be, as well as how the combination of chemicals removed will affect disease risk, if at all, and whether the processes used to alter the chemical makeup of cigarette smoke will introduce new chemicals that may even be more hazardous to health.

\section{Regulation of nicotine (section 907)}

Although some have argued that the FDA would be able to reduce nicotine levels to below a threshold level required for addiction, the Bill contains a clause that prohibits the FDA from lowering the nicotine level to zero (section 907(b)(3)(B)), which will likely be interpreted by the courts as intending to reserve to Congress the right to make decisions regarding the requirement that tobacco products be nonaddictive. This issue will certainly be tied up in the courts should the FDA decide to take such an action.

\section{Advertising restrictions (sections 906 and 12)}

Until the Supreme Court rules on what cigarette advertising restrictions, if any, will be considered constitutional, there is simply no evidence that the particular advertising restrictions in the Bill will be upheld. Philip Morris has already indicated that it will challenge these restrictions in court. ${ }^{12}$

Youth access regulations (sections 906, 12, and 13)

There is strong evidence that youth access regulations, as implemented in practice, are not effective in decreasing youth smoking. ${ }^{13-16}$

\section{SUMMARY AND WEIGHING OF POSITIVE AND NEGATIVE EFFECTS}

Based on the evidence, the Bill will likely have one positive effect-increasing adult smoking cessation slightly through stronger warning labels-and six negative effects: eroding the public perception of the inherent harms posed by cigarettes; creating the public perception that the problem is taken care of and reducing the allocation of state funding for effective tobacco control programmes and media campaigns; ending any serious threat to tobacco companies of damage from litigation; improving the public image of tobacco companies; ending the incentive for the development of truly reduced risk tobacco products; and institutionalising the problem of unsubstantiated health risk claims by cigarette marketers. There seems little doubt that on balance, the negative effects outweigh the positive. I conclude that the Family Smoking Prevention and Tobacco Control Act will be detrimental to the public's health.

\section{IMPLICATIONS OF FINDINGS}

Enactment of the Senate FDA Bill will have a chilling effect on tobacco control interventions that we know are effective, including comprehensive state level programmes, ${ }^{6}$ anti-smoking media campaigns, ${ }^{6} 91718$ and tobacco litigation. ${ }^{19-21}$ By diverting resources to any area where it is simply not politically feasible to achieve success, the promotion of FDA legislation is not only a waste of energy, but it is detracting from the state and local practice of tobacco control, which has been, and continues to be, tremendously successful in changing social norms and reducing tobacco use. ${ }^{21-23}$ Focusing our efforts on this doomed pathway instead of on interventions that are politically feasible and have been successful is simply snatching defeat from the jaws of victory.

\section{ACKNOWLEDGMENTS}

There are no conflicts of interest involving this work. No funding was involved in the preparation of this manuscript.

\section{REFERENCES}

1 Stokey E, Zeckhauser R. A primer for policy analysis. New York: WW Norton \& Company, 1978.

2 Bardach E. A practical guide for policy analysis: the eightfold path to more effective problem solving. New York: Chatham House Publishers, 2000.

3 Weimer DL, Vining AR. Policy analysis: concepts and practice, 3rd ed. Upper Saddle River, New Jersey: Prentice Hall, 1998.

4 Strahan EJ, White K, Fong GT, et al. Enhancing the effectiveness of tobacco package warning labels: a social psychological perspective. Tobacco Control 2002;11:183-90.

5 Hammond D, McDonald PW, Fong GT, et al. The impact of cigarette warning labels and smoke-free bylaws on smoking cessation: evidence from former smokers. Can J Public Health 2004;95:201-4.

6 Siegel M. The effectiveness of state-level tobacco control interventions: a review of program implementation and behavioral outcomes. Annu Rev Public Health 2002;23:45-71.

7 Rosenberg NJ, Siegel M. Use of corporate sponsorship as a tobacco marketing tool: a review of tobacco industry sponsorship in the USA, 1995-99. Tobacco Control 2001; 10:239-46.

8 United States Code. The Federal Cigarette Labeling and Advertising Act, 15 U.S.C. §§ 1331-1340 (Pub. L. 91-222, Sec. 2, April 1, 1970).

9 Siegel M. Mass media antismoking campaigns: a powerful tool for health promotion. Ann Intern Med 1998; 129:128-32.

10 Blum A. The Marlboro Grand Prix: circumvention of the television ban on tobacco advertising. N Engl J Med 1991;324:913-7. 
11 Siegel M. Counteracting tobacco motor sports sponsorship as a promotional tool: is the tobacco settlement enough? Am J Public Health 2001;91:1100-6.

12 Shaffrey MM. Cigarette-makers urge Congress to reject tobacco-quota-buyout bill. Winston-Salem Journal July 22 2004.

13 Siegel M, Biener L, Rigotti NA. The effect of local tobacco sales laws on adolescent smoking initiation. Prev Med 1999;29:334-42

14 Rigotti N, DiFranza JR, Chang Y, et al. The effect of enforcing tobacco-sales laws on adolescents' access to tobacco and smoking behavior. N Engl J Med 1997;337:1044-51.

15 Fichtenberg CM, Glantz SA. Youth access interventions do not affect youth smoking. Pediatrics 2002;109:1088-92.

16 Thomson CC, Gokhale M, Biener L, et al. Statewide evaluation of youth access ordinances in practice: effects of the implementation of community-level regulations in Massachusetts. J Public Health Manage Practice 2004; 10:481-9.

17 Blum A. Paid counter-advertising: proven strategy to combat tobacco use and promotion. Am J Prev Med 1994;10/3 suppl):8-10.

18 Rivara FP, Ebel ABE, Garrison MM, et al. Prevention of smoking-related deaths in the United States. Am J Prev Med 2004;27:118-25
19 Merzer M, Brecher EJ. The tobacco verdict: jurors calculated punishment-and a billion-dollar discount. The Miami Herald. July 16, 2000: 1A,21A.

20 Somers T. Jury to Big Tobacco: Pay \$145 billion; lawyers played hardball; jury followed suit. The Sun-Sentinel. July 15, 2000: 1A,10A.

21 US Department of Health and Human Services. Reducing tobacco use: a report of the Surgeon General. Atlanta, Georgia: US Department of Health and Human Services, Centers for Disease Control and Prevention, National Center for Chronic Disease Prevention and Health Promotion, Office on Smoking and Health, 2000.

22 National Cancer Institute. Changing adolescent smoking prevalence: where it is and why. Smoking and Tobacco Control Monograph No.14. Bethesda Maryland: US Department of Health and Human Services, National Institutes of Health, National Cancer Institute, 2001, NIH publication no.02-5086.

23 National Cancer Institute. State and local legislative action to reduce tobacco use. Smoking and Tobacco Control Monograph No. 11. Bethesda, Maryland: US Department of Health and Human Services, National Institutes of Health, National Cancer Institute, 2000.NIH publication no.004804 .

\section{FDA REGULATION}

\section{Opposition in search of a rationale: the case for Food and Drug Administration regulation M L Myers}

F or more than a decade, public health leaders have called for government regulation of tobacco products. The consensus in support of government regulation recognised that, absent strong new governmental authority, the tobacco industry would continue to do the following: pursue marketing practices that are deceptive, have a negative impact on children and discourage quitting; withhold information vital to public health scientists; secretly manipulate their products in ways that make them more dangerous and more addictive; market products that the public perceives to be less hazardous while having no incentive to market products that, in fact, deliver fewer toxins; and undermine prevention efforts by using unsubstantiated claims, such as "light" or "low tar", to keep people smoking.

To address these concerns, in May 2004 long time public health champions Senators Edward Kennedy and Mike DeWine and Congressman Henry Waxman introduced in the US Congress legislation granting the US Food and Drug Administration (FDA) sweeping regulatory authority over both new and existing tobacco products and their marketing. This legislation is consistent with or stronger than the regulatory principles established by a consensus of American public health groups as well as the recommendations of the Institute of Medicine of the National Academy of Sciences, the World Health Organization's Scientific Advisory Committee on Tobacco Product Regulation, and the WHO Framework Convention on Tobacco Control.

\section{ENDORSEMENTS}

The legislation was endorsed by former FDA Commissioner David Kessler, former Surgeon General C Everett Koop, 60 national organisations including the American Cancer Society, the American Lung Association, the American Medical Association, the American Public Health Association, and more than 400 affiliates of those organisations and other local public health groups. Conservatives in Congress, every tobacco company except Philip Morris, tobacco retailers, and tobacco advertisers, vigorously opposed the legislation.

Among its provisions, the legislation:

- Curtails many specific marketing practices that impact youth. In addition, it gives the FDA authority to further restrict tobacco marketing to the maximum extent permitted by the First Amendment to the US Constitution, ${ }^{1}$ the broadest authority Congress can give FDA. 


\section{Debate}

- Requires tobacco companies to disclose what is in each tobacco product by quantity in each brand and sub-brand, including all ingredients, constituents, and smoke constituents, and to promptly inform the FDA of any changes to the product ${ }^{2}$ providing FDA with unprecedented product information.

- Grants the FDA unprecedented authority to set toxicant exposure standards for and require changes in both current and future products to "protect the public health". The FDA may require the reduction or removal of any harmful ingredients or naturally occurring constituents, including smoke constituents. The FDA can also reduce nicotine to minuscule levels that do not lead to addiction. The FDA can take these steps without first having met the nearly impossible burden that such a proposed action will reduce the risk of disease. ${ }^{3}$ The FDA can also prohibit manufacturers from publicising that they meet new standards in order to prevent manufacturers from misleading consumers into believing that these products are safe or safer. This is the most sweeping authority any regulatory agency has ever possessed to require changes in tobacco products.

- Bans certain flavourings that make tobacco products more appealing to non-smokers and gives the FDA authority to ban still others.

- Prohibits the terms "light", "mild" or "low" and significantly improves the health warnings on tobacco products and their ads. ${ }^{4}$

- Prohibits reduced risk claims until the FDA first determines both that the product: (1) as actually used will significantly reduce the risk of disease to individual consumers; and (2) as marketed will benefit the population as a whole taking into account its impact on initiation, quitting, and relapse.

- Prevents tobacco companies from using reduced exposure claims to circumvent the law by holding that a reduced exposure claim is a health claim. Strict standards are set for such exposure claims. They are permitted only so long as the best available science is inadequate to meet the more rigorous standard for a specific health claim and even then are permitted only when: (1) the best available science demonstrates that a measurable and substantial reduction in risk is anticipated; and (2) the manufacturer can prove that consumers will not be misled into believing that the product has been proven less hazardous.

- Gives the FDA the authority to set rules for how so called reduced risk products will be marketed, and requires post-market surveillance of their actual usage. ${ }^{5}$ This will encourage manufacturers to produce products that actually reduce the risk of disease by only permitting claims that can be proven and will eliminate the unproven claims now being used to mislead smokers.

\section{REASONS FOR OPPOSITION}

Perhaps one reason for opposition is that there are misconceptions about the legislation. Contrary to the interpretation of some critics it does not focus on just new products or misleading claims. It gives the FDA broad authority over both current and new products to "to protect the public health". The FDA is authorised to do what is necessary to reduce the number of people who die from tobacco use.

Other criticisms are also misplaced. Adoption of regulatory authority over the tobacco industry will not create the impression that the tobacco problem is resolved. Proponents of regulation recognise that regulation is not a panacea, but an additional tool. Regulation will also not add to the legitimacy of tobacco products that already arises from the government's current acceptance of these products, but it can rein in tobacco company behaviour.* $^{*}$

Once Philip Morris endorsed the legislation, opposition arose from a number of individuals who had not opposed previous bills that were either similar or contained weaker authority to require changes in existing products or to regulate so called reduced risk products.

Underlying the opposition is a fundamental issue-a belief that any legislation endorsed by Philip Morris cannot be good for public health. Philip Morris broke with the rest of the industry when it supported this Bill. It accepted proposals the public health community had long sought and the company had opposed. Philip Morris' support is cause for careful scrutiny but not a reason for rejection. Philip Morris has supported the Framework Convention for Tobacco Control and legislation to curb internet sales of tobacco and smuggling, yet these initiatives deserve support. This may be one case where what one company decides is in its interest may be bad for the industry as a whole and, therefore, good for public health.

Somehow, the critics of this legislation argue that giving the government authority to curtail tobacco marketing, expand youth access restrictions, modify current and existing tobacco products, improve health warnings, eliminate unsubstantiated and misleading health claims, and require tobacco industry disclosures is bad for public health. The alternative to government regulation is not the elimination of tobacco; it is the status quo. This Bill addresses longstanding problems and does so in ways that have long been endorsed by public health experts.

*Some critics have expressed concern that this legislation will eliminate the litigation threat to tobacco companies. Section 917(b) states specifically that the Bill does not modify the liability of a tobacco company. More importantly, if the legislation resulted in less wrongdoing by tobacco companies and, therefore, gave consumers less of a reason to sue them while saving lives, the net impact would be positive. 
This Bill would provide the most comprehensive regulatory approach ever adopted. The one thing we know for certain: without this kind of legislation the tobacco industry will continue to manipulate its products without our knowledge and devise its marketing in ways that are designed to keep people smoking without regard to the harm that cigarettes cause.

\section{REFERENCES}

1 H. R. 4520 (American Jobs Creation Act of 2004), Title XI (Provisions Relating to Tobacco), Chapter IX,

Section 906(d), Section 1112 (July 15, 2004).

2 Id at Section 904.

$3 \mathrm{Id}$ at Section 907.

$4 \mathrm{Id}$ at Section 911, Section 1121.

5 Id at Section 911.

The Lighter Side

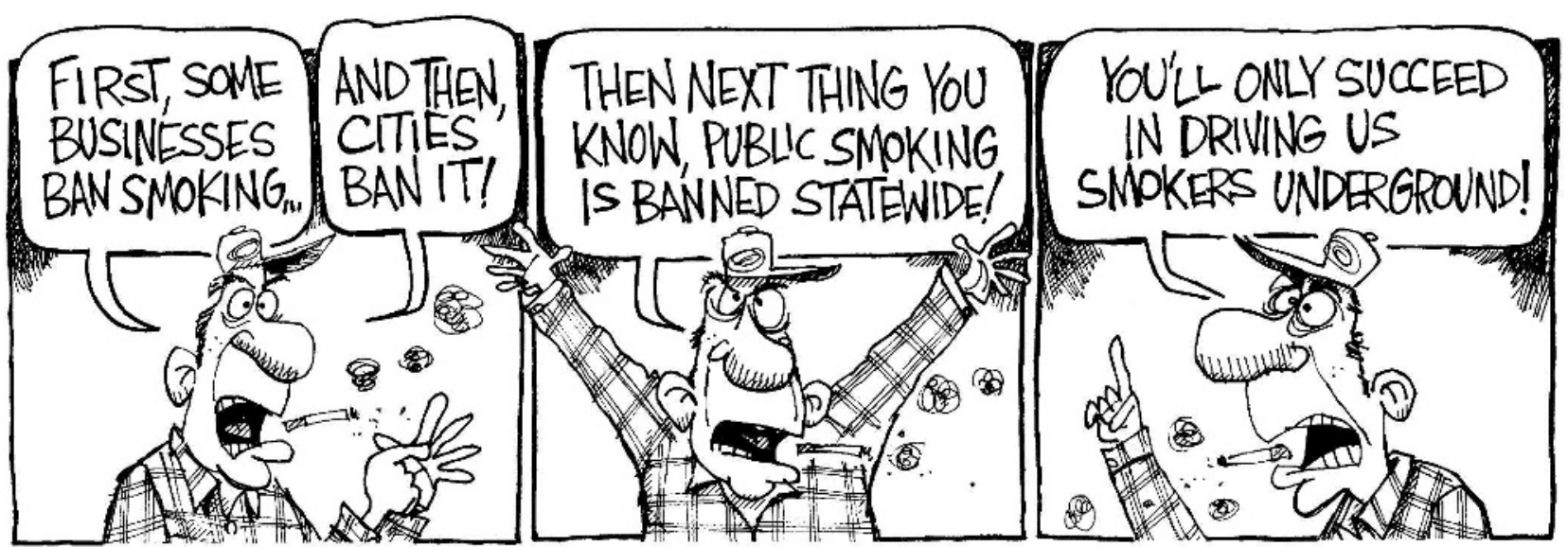

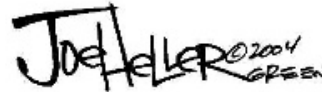

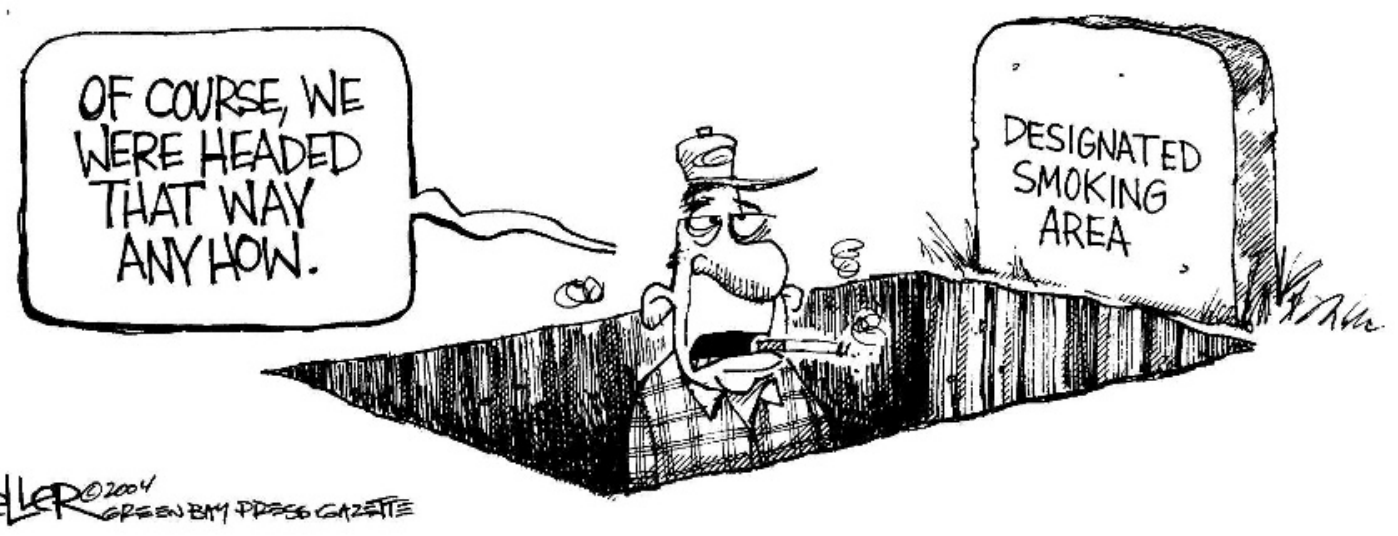

(c) Joe Heller, Green Bay Press-Gazette. 